The various phases of the oscillation did not take place at the different stations at the same absolute time, or local time, but in every instance were associated with the time of maximum obscuration of the sun. The duration of the oscillation was apparently about the same as that of the eclipse, about two and a half hours. The range of the oscillation was about one minute in arc for declination, and about eight units in the fifth decimal C.G.S. for horizontal intensity, that is, to about $\mathrm{I} / 2800$ th part of the absolute horizontal intensity. The general effect was to deflect the declination needle to the west, and decrease the horizontal intensity, before the time of maximum obscuration, the movement afterwards being in both cases in the opposite direction. The analysis indicates that the cause producing the magnetic oscillation was situated outside of the earth's crust, the presumption being very strong that the oscillation is to be referred to some change produced in the upper atmospheric regions by the abstraction of the sun's rays, due to interposition of the moon.

Dr. Bauer expresses himself as having been in doubt before making the observations as to whether any magnetic effect referable to the eclipse would reveal itself, and adds that he was afterwards slow to conclude that the magnetic oscillation observed was not accidentally connected with the eclipse, until he had made such exhaustive examination of every point involved as justified him in formulating a definite conclusion. The result is interesting, and makes it desirable, as he says, that every opportunity should in future be taken to obtain during eclipses, simultaneous magnetic, atmosphericelectric and meteorological observations at as many stations as possible.

It is to be remarked that, although Dr. Bauer eventually speaks with some confidence as to the magnetic movement observed having relation with the eclipse, the movement in question was small, and, abstractedly speaking, much too small on which to found any certain conclusion, considering the abundance of magnetic movements of similar and even greater magnitude. The circumstance that seems really to give weight to the conclusion drawn is the statement that the various phases of the magnetic oscillation were associated with the time of maximum obscuration of the sun. Confirmation of this circumstance is therefore what is now to be desired.

Following the paper there is printed an appeal for international co-operation in magnetic and allied observations during the total solar eclipse of May i 7 next.

\section{William Ellis.}

\section{PROF. H. A. ROWLAND.}

HENRY AUGUSTUS ROWLAND was born in H 1848 . He was educated as an engineer, and graduated at the Rensselaer Polytechnic at Troy, New York, in 1870 . After one year's experience as a railway engineer on the Western New York line, and a second spent as instructor in natural science at Wooster, Ohio, he returned to his college to share in its teaching, becoming an assistant professor in 1874 . Two years later, in 1876 , after spending a year under Helmholtz in Berlin he took office as the first professor of physics at the newly founded Johns Hopkins University. Baltimore remained his home until his death, on April I6, at the early age of fifty-three years.

His work at Berlin on the magnetic efforts due to a moving body when carrying an electric charge brought him at once into fame. The result was published by von Helmholtz in 1876 , and is thus described by Maxwell in a metrical letter to Tait, written in June, I877. Tait had inquired, also in verse, as to the electric effects to be expected if a disc of ebonite carrying a charge were made to rotate in its own plane, and Maxwell writes: NO. I 644, vOL. 64]
The mounted disk of ebonite

Has whirled before nor whirled in vain,

Rowland of Troy, that doughty knight,

Convection currents did obtain,

In such a disk, of power to wheedle

From its loved north the subtle needle.

Rowland showed by the direct effects produced on a magnetic needle that a charged body in motion gave rise to a magnetic field just as though it were a current whose strength depended on the product of the charge and the velocity.

This result is of fundamental importance to electrical theory; it was confirmed by Rowland and Hutchinson in 1889 , and has been generally accepted as an established fact. Within the last few months, however, Cremieu has published an account of a repetition of Rowland's experiments which has led him to a negative result ; the question just at the present moment appears to need further investigation.

Rowland's appointment at Baltimore was rapidly followed by a series of brilliant researches, each of the first importance. His determination of the unit of resistance came first. This was published in 1878 . The original B.A. units were constructed by the Electrical Standards Committee in $1863^{-4}$ to represent $10^{9}$ C.G.S. units of resistance ; according to Kohlrausch's results in 1870 they were 2 per cent. too high, while according to Lorenz (I873) they were 2 per cent. too low. Rowland's paper contains an able criticism of the old experiments and a detailed account of his own which led him to the number $9912 \times 10^{9}$ C.G.S. units as the value of the B.A. units. Further experiments in 1887 reduced this to $9864 \times 10^{5 *}$. The value now generally accepted is $98653 \times$ IO $^{9}$. Rowland himself employed a modification of Kirchhoff's original method, in which the induction current in a secondary circuit produced by reversing a measured primary current in a neighbouring circuit is observed.

In 1879 Rowland presented to the American Academy of Arts and Sciences his paper on the mechanical equivalent of heat, with subsidiary experiments on the variation of the mercurial from the air thermometer, and on the variation of the specific heat of water. To attempt to give any account of the contents of this classic work would occupy too much space. To appreciate its value and to realise the skill and the ingenuity of its author it must be studied itself. More is known now about exact thermometry and the precautions necessary in using a mercury thermometer, and so it has come about that some corrections are necessary in Rowland's work, specially in that part of it which deals with the relation between the scales of the mercury and the air thermometer. These corrections were made at the Johns Hopkins University by Messrs. Day and Wardner and Mallory; but this fact detracts nothing from the importance of his investigation, and among the many determinations of the value of Joule's equivalent, Rowland's will always remain in the first rank.

Passing over, for the present, much work of great value, among which we may note his investigations into the magnetic permeability of various substances, published in the Philosophical Magazine for 1873 and 1874 , and his theory of Hall's effect, we come next to the year 1882 , when Rowland gave to the Physical Society of London an account of his concave grating. This is published in the Philosaphical Magazine for September, 1883 .

The results of this discovery are well known. A new weapon was placed in the hands of spectroscopists; it became possible to photograph spectra directly without the use of prisms or lenses, and with a greatly increased dispersion and resolving power; the beautiful maps issued at a later date by Rowland himself, and by Higgs of Liverpool, are striking evidences of the value of the grating; the additions to our knowledge arising from this one discovery are already enormous; much has been achieved which, without it, would have been impossible. 
Rowland's own researches with his grating are summed up in his map of the solar spectrum and his table of the wave-lengths of the elements, published in 1893 (Phil. Mag., July, 1893, reprinted from Astronomy- and AstroPhysics.)

Of late years he gave much time and attention to a system of multiple telegraphy; this was shown working at the Paris Exhibition last year.

Enough has been written, perhaps, to indicate the debt physical science owes to Rowland; it is said he never received any regular instruction in physics; he was an engineer, and to this, in great measure, his success is due. The accuracy of his work on the ohm depends on the care he took to construct his induction coils so that their dimensions could be accurately measured; he dealt with the determination of the mechanical equivalent as an engineering problem; he employed a large mass of water and used steam power to rotate his paddle at a speed sufficient to make the resulting rise in temperature one that could be measured with accuracy.

The theory of the concave grating was his, but its success was due to the fact that Rowland had made an almost perfect screw; the method he employed in this in given in his article, "Screw," in the "Encyclopredia Britannica."

He lived for his work, but in his earlier days he was passionately fond of riding. Some years after the publication of the paper on the mechanical equivalent he was awarded a prize for it by one of the Italian Academies; about the same time he won a steeple chase, riding his own horse; he hardly knew which event gave him the greater pleasure. Another time, passing through England on his way home from the Continent, he had three days to spare. One of these was passed at Cambridge discussing electrical measurements, the other two were spent in a hurried visit to Exmoor to get a run with the staghounds. Twenty years ago he was a frequent visitor to England, and attended several of the meetings of the British Association; recently his visits were much less frequent. His friends here were aware that he was not well; some few weeks ago it was known that he had had a serious illness, but the news then was that he was better and on the road to recovery; however, an operation proved necessary, and he never recovered from its effects.

Thus within the last few months physical science is the poorer by the deaths of two of the most brilliant of the followers of Maxwell-Fitzgerald and Rowland; two who were foremost among those who have given to the theory of Faraday and Maxwell the right to claim the position of the theory of the electro-magnetic field.

R. T. G.

\section{PROF. FRANÇOIS MARIE RAOULT.}

FRANÇOIS RAOULT, professor of chemistry at F Grenoble, died there on April I after a short illness. In him France has lost one of her most distinguished men of science, whose discoveries have supplied material for theoretical considerations which, within the past fifteen years, have had a most profound influence on chemistry and physics.

Raoult was born on May 10, 1830, at Fournes (Nord). His father, an officer in the local customs' service of Villers Cotterêts (Aisne), sent the boy to school at Laon, with the intention of his afterwards entering Government service. But Raoult's tastes lay in a different direction ; and with the full consent of his father he finished his school career at Paris, and entered the scholastic profession. He began his teaching career at the age of 23 in the Lycée at Reims, and was shortly afterwards transferred to the Collège of Saint Dié; while there he NO. I 644, VOL. 64] graduated as B. ès Lettres, and B. ès Sciences, passed his "Licencié" examination, and was appointed "Agrégé" of special secondary instruction. On presenting a thesis on "The Electromotive Forces of Voltaic Cells" he gained the title of "Docteur ès Sciences Physiques," and four years later, in 1870 , he obtained the chair of chemistry at Grenoble, where he passed the rest of his life in constant labour in teaching and research during a period of 31 years. In 1889 he was elected "doyen," or dean of the faculty, and was re-elected to this important office four times. He occupied himself largely during the last dozen years in the reorganisation of the Faculty of Science, leading to the creation of a local university at Grenoble in 1896.

The author of this notice was once informed by Raoult that he independently discovered Faraday's and Ohm's laws; he had begun to experiment on the passage of electricity through solutions before he had acquired any real knowledge of what had already been achieved. On mentioning the fact to his scientific friends at Paris he learned, to his great disappointment, that his discoveries had been anticipated; but he took comfort in the thought that if he were able to make such discoveries, of which the importance is universally recognised, he must also be able to advance science in other directions. His first scientific work, published as his thesis for the doctorate, has already been mentioned; it was published in 1863 , and until I870 he devoted himself to a study of the chemical effects of the electric current, trying to distinguish between the heat evolved by chemical reactions and that due to the electric current in the voltaic cell. From 1870 to 1886 his attention was given to subjects of a more purely chemical nature, such as the extent of inversion of cane sugar under the influence of solar radiation ; the absorption of ammonia by saline solutions; the presence of copper and zinc in the animal organism; the carbonates of calcium, strontium and barium ; and the influence of carbonic anhydride on respiration. His work on the absorption of ammonia led him to consider the freezing-points of the saline solutions of that gas (1878); and from that date onwards he busied himself with the freezing- and boiling-points of solutions in water and in other solvents of salts and organic compounds, publishing his results in no less than 57 memoirs in various scientific journals. His last publication, "La cryoscopie," was published in the present year (Collection Scientia, Carré et Naud).

Most of Raoult's apparatus was constructed with his own hands ; he was rather given to accurate experimentation than to the evolution of theories. The vast mass of evidence which he accumulated relative to the lowering of the freezing-points and of the vapour-pressures of solvents by the presence of dissolved substances made it possible for van't Hoff to draw the important deductions relative to the connection of these phenomena with osmotic pressure and with the ionic theory of Arrhenius, which will ever shed lustre on his name. And to the practical chemist Raoult's work furnished a means of determining the molecular weights of non-volatile substancesmethods familiar to every student of chemistry.

His labours met with ample, though tardy, recognition. In 1889 he was awarded the Prix Lecaze, of 10,000 francs; and in the same year he was made correspondant de l'Institut de France. In 1895 he received the biennial prize of the Institute ; in 1892 he was the Davy medallist of the Royal Society, and in 1898 he was elected a Foreign Fellow of the Chemical Society of London. $\mathrm{He}$ was chosen Chevalier de la Legion d'Honneur in I89o, raised to Officier in 1895, and last year obtained the muchcoveted title of Commandeur. He was a member of many foreign academies and scientific societies.

Though modest and retiring, Raoult's devotion to his work, dignity of character and sweetness of temper gained him many friends. $\mathrm{He}$ was not an ambitious 